absorption of iron preparations in different individuals. Thus iron from ferrous sulphate in group 3 was better absorbed than in groups 4 and 5 , even taking into consideration the larger dose of iron in group 3 (65 mg. as opposed to $37 \mathrm{mg}$.). The ferrous sulphate tablets in group 3 were supplied by a different

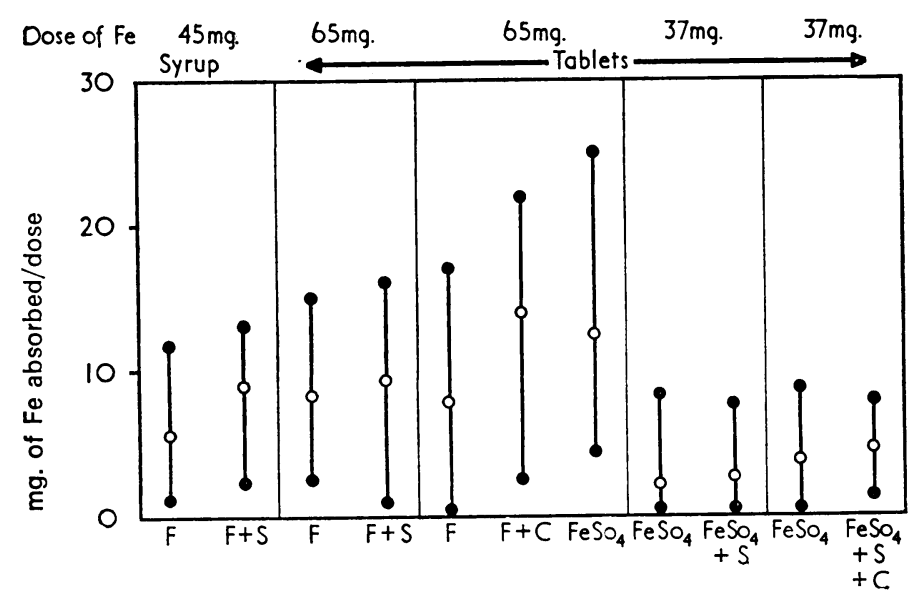

FIG. 4.-Range and mean absorption of iron in terms of milligrams per dose in all five groups of subjects.

source from groups 4 and 5, but there does not appear to be any significant difference in the preparation of the tablets. It would seem, therefore, that the greater absorption in group 3 can be accounted for only by variation in absorption between individuals within the groups.

The majority of observations on the effectiveness of different iron preparations have been made on different individuals, and for such studies to be valid it is obvious that large groups require to be studied. The use of radioactive labelled material has the advantage that it enables comparisons to be made in individual subjects.

We are indebted to the pharmaceutical firms Astra Hewlett and Glaxo Laboratories for supplies of ${ }^{50} \mathrm{Fe}$-labelled tablets. The work was supported in part by a grant from the Medical Research Council. Miss M. Alcock and Miss S. Howes provided valuable technical assistance.

\section{REFERENCES}

Brise, H., and Hallberg, L. (1962). Acta Medica Scandinavica, Suppl. No. 376, p. 59.

Callender, S. T., and Warner, G. T. (1968). American fournal of Clinical Nutrition, 21, 1170.

Callender, S. T., Witts, L. J., Warner, G. T., and Oliver, R. (1966). British fournal of Haematology, 12, 276.

Cochran, W. G., and Cox, G. M. (1957). Experimental Design, p. 127. New York, Wiley.

Hallberg, L., and Sölvell, L. (1966). Acta Medica Scandinavica, Suppl. No. 459 , p. 23.

Warner, G. T., and Oliver, R. (1966). Physics in Medicine and Biology, 11,83 .

\title{
Pancreatic Calcification: A Report of 45 Cases
}

\section{E. O. OLURIN,* M.B., F.R.C.S., F.R.C.S.ED. ; OYINADE OLURIN, † M.B., CH.B., D.o.}

ummary: Forty-five cases of pancreatic calcification $S$ are reported, and it is shown that in Western Nigeria this malady afflicts younger people than in Europe and the United States of America. Males and females seem about equally affected in Western Nigeria, whereas it predominantly affects males in France, Britain, and North America. Diabetes mellitus was the commonest complication in this series, and brought many patients to the doctor. In this series chronic relapsing pancreatitis was a rare cause; there was no history of alcoholism; and protein malnutrition was thought to be responsible for pancreatic calcification in over $\mathbf{9 0 \%}$ of the patients.

\section{Introduction}

Clinical pancreatic calcification is usually diagnosed radiologically in the routine investigation of its complications and sometimes as an incidental finding in the radiological investigation of upper abdominal pain. Graaf $^{1}$ was reported to have first recorded pancreatic calculi in 1667. Haggard and Kirtley ${ }^{2}$ in 1936 collected 204 cases from the literature covering a period of 201 years. Since that comprehensive review there have been a number of smaller reviews and case reports. Authors in the United States of America include Gillies, ${ }^{3}$ King and Waghelstein, ${ }^{4}$ Lionello, Ficarra, and Ryan, ${ }^{5}$ Mayo, ${ }^{6}$ Martin and Canseco, ${ }^{7}$ Wirts and Snape, ${ }^{8}$ Domzalski, ${ }^{9}$ Gambill and Pugh, ${ }^{11}$ Edmondson, Bullock, and Mehl, ${ }^{11}$ and Kneidel. ${ }^{12}$ Recently, important contributions have been made by Howat ${ }^{1314}$ and Pollock $^{15}$ in Great Britain, by Sarles et al. ${ }^{16}$ in France, and by Marks and Bank ${ }^{17}$ of South Africa. Pancreatic calcifications have also been reported from some tropical countries: Zuidema $^{18} 19$ in Indonesia, Mahadevan ${ }^{20}$ and Ratnaike and Rajasuriya ${ }^{21}$ in India, Shaper ${ }^{22}$ and Banwell et al..$^{23}$ in Uganda, and Kinnear ${ }^{24}$ in Nigeria.

There seem to be pronounced differences in the clinical features and aetiology of pancreatic calcification as obtain in Western Europe and the. United States of America on the one hand and in the tropical countries on the other. The aim of this paper is to analyse 45 cases of pancreatic calcification seen in University College Hospital, Ibadan, and to illustrate the similarities and differences in their features as compared with cases reported in other countries. We shall not differentiate between pancreatic calculi, so-called pancreatic lithiasis, and disseminated pancreatic calcification, because it is usually impossible to differentiate between the two types clinically, radiologically, and pathologically. In nearly all cases both types coexist in the same pancreas. Indeed, as $\mathrm{King}^{25}$ said, a single or several large calculi confined to the ducts are generally the exception. Like Gambill and Pugh, ${ }^{10}$ we use the term "pancreatic calcification" to denote calcareous deposits in any 
part of the pancreas, both in the ductal system and in the parenchyma.

\section{Material and Method}

Between 1957 and 196845 patients with pancreatic calcification were seen in this hospital. The diagnosis was made from plain radiological films of the abdomen in 40 patients and from barium-meal examination in four. In one patient the diagnosis was clinically suspected but death occurred before radiological examination; at necropsy calcified pancreas was found. The case-notes of all these patients were analysed in detail. It has been possible to follow up regularly 13 patients, all of whom were carefully questioned about their symptoms and treatment. Necropsy was performed on 4 of the 45 patients. Those with mucoviscidosis and other types of pancreatic disease were excluded from this study. Pancreatic calcifications found accidentally at necropsy without previous clinical suspicion were not included.

\section{Results}

Age and Sex.-The youngest patients were four 10-year-olds. The oldest patient was 65 . Thirty-one $(68 \cdot 8 \%)$ were aged 20 years or under, seven $(15.5 \%)$ were aged 21 to 30 , and six $(13.3 \%)$ were aged 31 to 40 . There were 28 males and 17 females. The age and sex distribution is given in Table I.

TABLE I.-Age and Sex Distribution in 45 Cases of Pancreatic

\begin{tabular}{lc|c|c|c|c}
\multicolumn{6}{c}{ Calcification } \\
\hline & Age: & $\leqslant 20$ & $21-30$ & $31-40$ & $60+$ \\
\hline Males &.. & 17 & 3 & 5 & 1 \\
Females & $\cdots$ & 14 & 4 & 1 & \\
\hline
\end{tabular}

\section{Symptoms}

Diabetes mellitus was the reason for seeking medical attention in 37 of the 45 patients (82\%) (Table II). The chief complaints were polyuria, polydipsia, and loss of weight. Four patients were first seen in hyperglycaemic coma. Pancreatic calcification was often diagnosed at the diabetic clinic by routine radiological examination of the abdomen (Figs. 1 and 2).

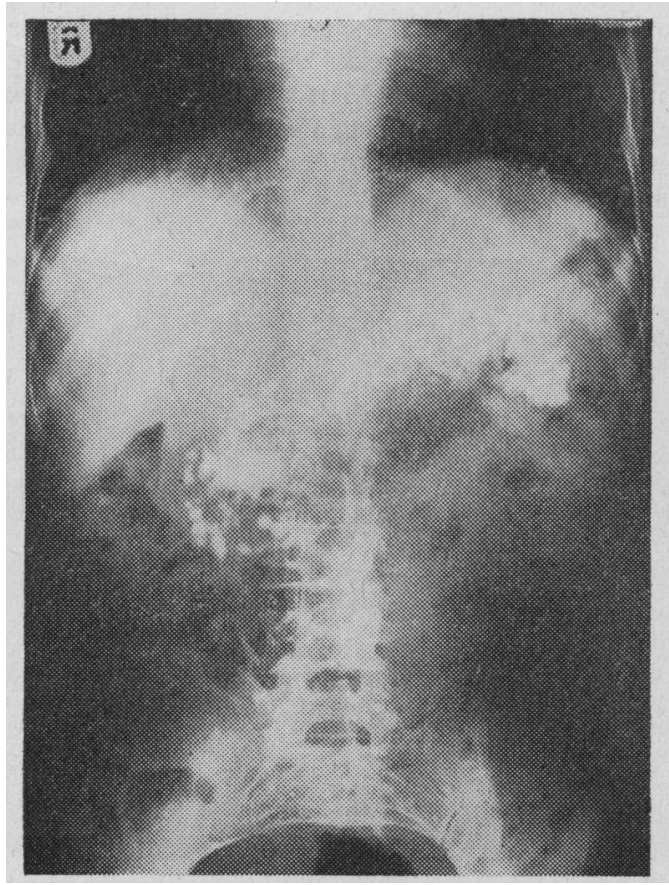

FIG. 1.-Radiological film of abdomen, showing extensive calcification of pancreas.
In 36 cases the diabetes was of the insulin-resistant type and the patients required large doses of insulin for stabilization and maintenance. They were difficult to control, and eight were

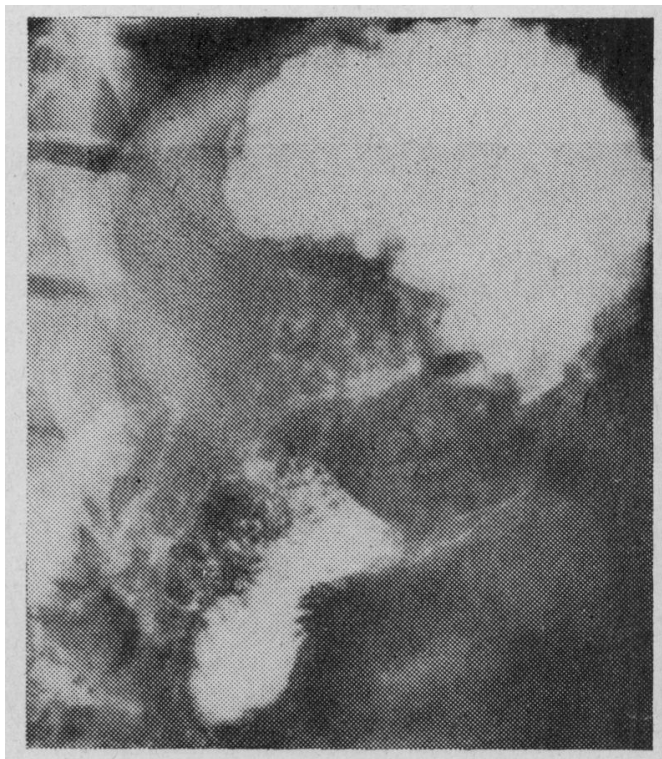

FIG. 2.-Radiological film of abdomen after barium meal, oblique view. Note calcification of pancreas, especially above the lesser curvature.

repeatedly admitted in hyperglycaemic semicoma or coma. One of these eight eventually died in hyperglycaemic coma a few hours after the fourth admission (Figs. 3 and 4). Four others were lost to follow-up.

TABLE II.-Clinical Features in 45 Cases of Pancreatic Calcification

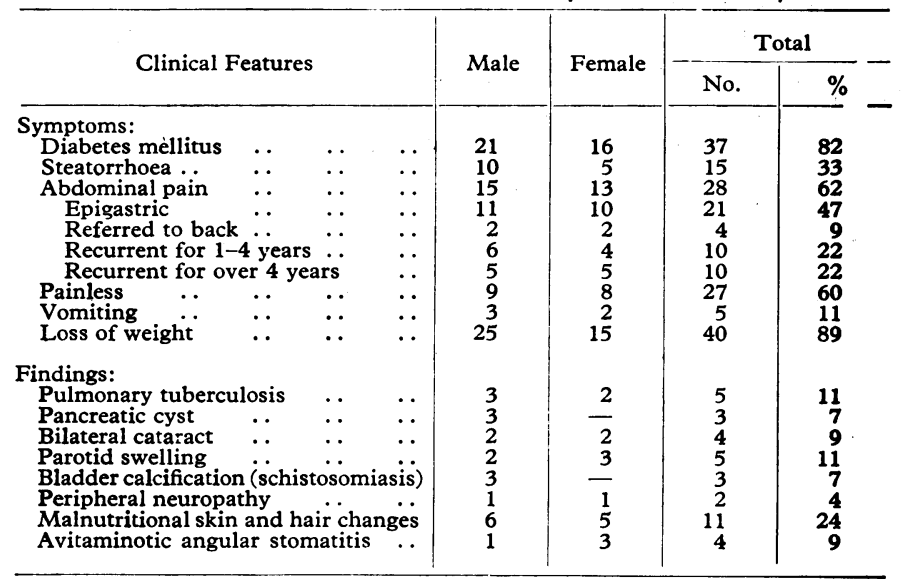

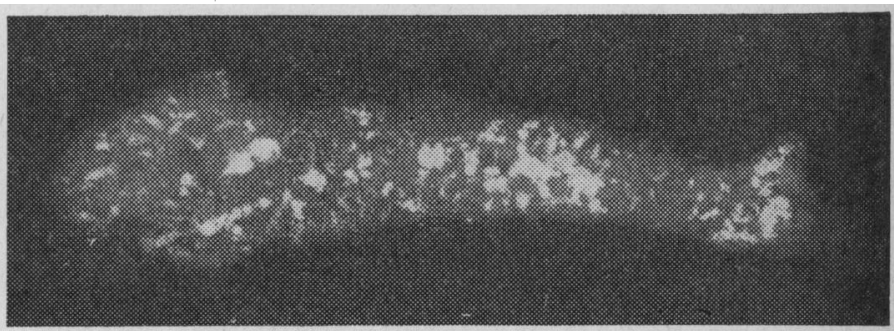

FIG. 3.-Radiological film of pancreas removed at necropsy.

Abdominal pain was quite prominent in their symptomatology. Twenty-eight patients had abdominal pain at one stage or another in the course of their illness. The history of abdominal pain was volunteered by 18 patients and it was extracted by direct leading questions in 10 . It was located in the upper abdomen, invariably epigastric, in 21 patients and radiated to the back in only four. In 10 patients the pain was 
recurrent for over four years and in another 10 from one to four years. In the remainder the period of the pain varied from a few days to some months. It was very severe in four patients, moderate in 12 , and mildly tolerable in the others. There was no history of abdominal pain at all in 17 patients (38\%). Vomiting was relatively uncommon. It occurred in five patients, and these had very severe epigastric recurrent pain.

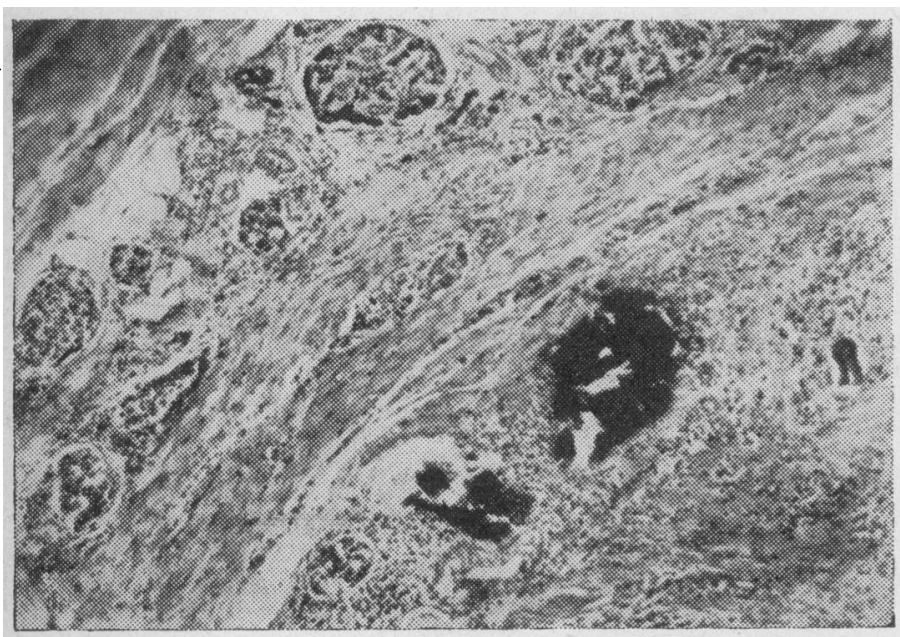

FIG. 4.-Photomicrograph of section of pancreas, showing extensive fibrosis, atrophy of acini, and calcification. (H. and $\mathrm{E}$. $\times 80$.)

Diarrhoea was the chief complaint in three patients. Clinical and laboratory steatorrhoea (fat balance tests) was found in 15 patients $(33 \%)$ including the three who complained of diarrhoea. There was history of weight loss in 30 patients (67\%), though 40 of the $45(89 \%)$ were found to be below the normal weight for their age and sex (see Table II). Parotid swellings were observed in five patients. There were malnutritional hair and skin changes in 11, and angular stomatitis in four. The serum albumin was below $2.5 \mathrm{~g} . / 100 \mathrm{ml}$. of blood in 11 out of 18 patients where details were available (Table III) (normal range for Western Nigeria $2.5-4.5$ g./ $100 \mathrm{ml}$.).

TABLE III.-Analysis of Relevant Biochemical Data Where Details are Available

\begin{tabular}{|c|c|c|c|c|c|}
\hline \multirow[b]{2}{*}{$\underset{\text { amylase }}{\text { Serum }}$} & & & & \multicolumn{2}{|c|}{ No. of Cases } \\
\hline & $\begin{array}{l}\text { 0-250 Somogyi units } \\
251-700 \text { Somogyi units } \\
701-1,000 \text { Somogyi units } \\
\text { Over } 1,000 \text { Somogyi units } \\
\text { Not known .. . . }\end{array}$ & $\begin{array}{l}\because \\
\because \\
\because\end{array}$ & $\begin{array}{l}\because \\
\because \\
\because\end{array}$ & $\begin{array}{l}\ldots \\
\because \\
\cdots\end{array}$ & $\begin{array}{l}33 \\
5 \\
\text { Nil } \\
3 \\
4\end{array}$ \\
\hline$\underset{\text { protein }}{\text { Serum }}$ & $\left\{\begin{array}{l}\text { Albumin less than } 2.5 \mathrm{~g} / 110 \\
\text { Albumin more than } 2.5 \mathrm{~g} .1 \\
\text { Not known } \ldots\end{array}\right.$ & $\begin{array}{l}0 \mathrm{ml} \\
100 \mathrm{ml} \\
\ldots\end{array}$ & 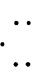 & $\because$ & $\begin{array}{r}11 \\
7 \\
27\end{array}$ \\
\hline$\underset{\text { calcium }}{\text { Serum }}$ & $\left\{\begin{array}{l}9-11 \mathrm{mg} . / 100 \mathrm{ml} . \\
\text { Not known } \ldots\end{array}\right.$ & $\because$ & $\because$ & $\because$. & $\begin{array}{l}20 \\
25\end{array}$ \\
\hline
\end{tabular}

Pulmonary tuberculosis was accidentally found by radiology in five patients. Pancreatic cyst was responsible for symptoms that brought three patients to the hospital. None of the three was diabetic. One of them had had epigastric pain for three years, vomiting on and off for about two years, and two episodes of melaena for which no cause was found at operation (Fig. 5). Four patients complained of failing vision in both eyes of relatively rapid onset. They had bilateral cataracts of diabetic type; two of them were under 18 years of age.

Chronic relapsing pancreatitis was diagnosed in three patients. One suffered from recurrent epigastric pain for about eight years, and during one of the bouts of pain the serum amylase was 1,920 Somogyi units $/ 100 \mathrm{ml}$. of blood. Another patient had recurrent abdominal pain with vomiting on and off for "many" years with repeatedly raised serum amylase; on one occasion it was 2,100 Somogyi units $/ 100 \mathrm{ml}$. The third patient also had recurrent abdominal pain and diabetes for about 10 years and on one occasion the serum amylase was 1,210 Somogyi units $/ 100 \mathrm{ml}$. In the three other patients provisional diagnosis of chronic relapsing pancreatitis was not sustained by any rise of serum amylase.

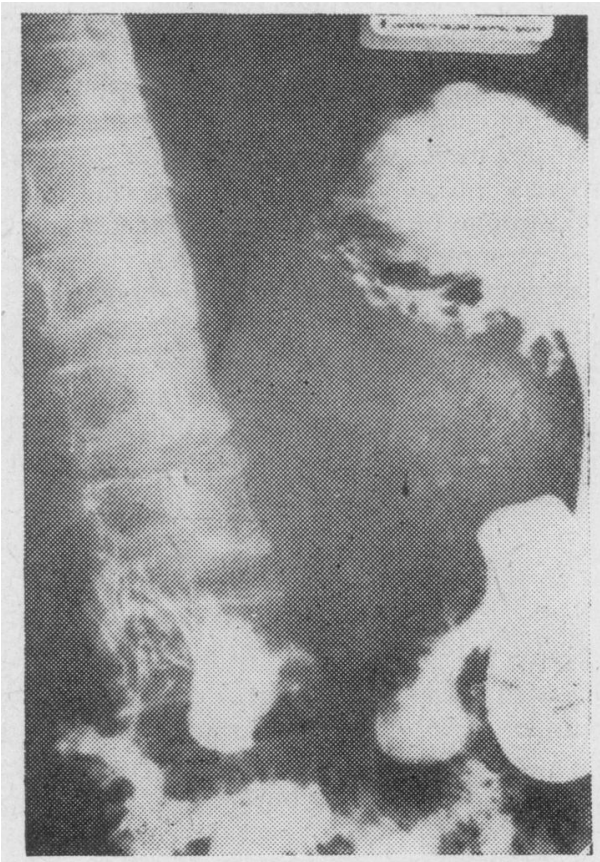

FIG. 5.-Radiological film of abdomen, oblique lateral view, after barium meal, showing anterior displacement of stomach by a pan-

creatic cyst in a calcified pancreas.

Schistosomiasis (Schistosoma haematobium) was associated with pancreatic calcification in three patients. In one of them both the pancreas and the urinary bladder were calcified and there were schistosoma ova in the urine on the first visit. In the second diabetic patient the urinary bladder was calcified when first seen in December 1963 and there were schistosoma ova in the urine. By June 1965 pancreatic calcification was found for the first time radiologically. The third patient was a man of about 40 . He was first seen and admitted to hospital in a semicomatose state on 14 April 1964. He died on 17 April from a profuse gastrointestinal haemorrhage. Necropsy revealed a chronic duodenal ulcer from which he bled to death. The ureters, urinary bladder, and the pancreas were heavily calcified. Microscopically, the pancreas contained heavily calcified schistosoma ova (Fig. 6). Many calcified schistosoma ova were present in the ureters, urinary bladder, liver, walls of pulmonary arteries, arterioles, veins and capillaries, and three abdominal lymph nodes.

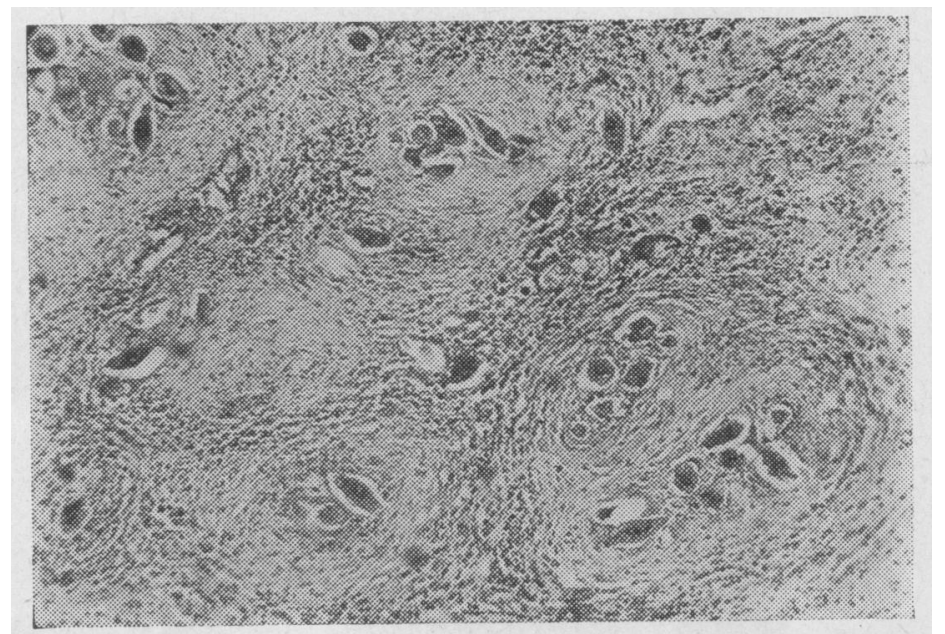

FIG. 6.-Photomicrograph of section of pancreas, showing many calcified schistosome ova. (H. and E. $\times 80$.) 
Internal haemorrhage occurred in three patients: one aged 18 died of subarachnoid haemorrhage, another aged 40 died of bleeding chronic duodenal ulcer, and the third had two episodes of melaena for which no cause was found.

One patient had a non-functioning gall bladder. There were no calculi in either the gall bladder or the common bile duct. She had no history of obstructive jaundice.

\section{Treatment}

Thirty-six patients with diabetes mellitus were treated with insulin. All of them required initial admission for stabilization, and a good number were readmitted several times for restabilization because they were difficult to control. Most of them needed high doses of insulin for maintenance. Only one patient, aged 18, was controlled with chlorpropamide. All those who had malabsorption responded satisfactorily to pancreatin granules.

Three patients with severe recurrent pain had surgical operations for relief of pain. One of them had had truncal vagotomy in another hospital, with relief of pain. He reported to University College Hospital two years later with diarrhoea and steatorrhoea. The malabsorption responded well to pancreatin, though he still had occasional bouts of post-vagotomy diarrhoea with diminishing severity. The other two patients had caudal pancreatectomy and drainage of the remaining pancreas to a Roux loop of jejunum. This procedure relieved the pain initially but the two patients were lost to follow-up. One of the two had cholecystectomy performed for a non-functioning stoneless gall bladder. Four other patients with epigastric pain refused operation. Three of them have regularly attended the follow-up diabetic clinic. Happily their pains have either disappeared or become tolerably mild once the diabetes was well controlled.

The three patients with pancreatic cysts had surgical operations. In each case the cyst was internally drained by cystogastrostomy with initial satisfactory result. Two of them have not been seen again since they were discharged. The third has done very well, and postoperative barium-meal examination six months after surgery showed complete absence of the cyst.

The four patients with diabetic cataracts had extraction of the cataract performed with good results.

\section{Discussion}

The 45 patients reviewed are all Nigerians. Thirty-five of them come from Western Nigeria, where this hospital is situated. Ten patients were referred from other parts of the country. The poor follow-up record in this hospital has been commented on by Kinnear. ${ }^{24}$ Many of the patients came from distant towns and villages and had no relations in Ibadan; thus accommodation was often impossible. For some it was difficult to find enough money for the rather frequent visits that diabetic follow-up entails. Many of the diabetics could be treated in hospitals nearer to their homes. When the pain which brought many of them to this hospital disappeared or became tolerable most of them could not see the point of repeated visits. Most of the patients who kept the follow-up dates were either fairly well educated or they lived near the hospital.

\section{Age and Sex}

Of the 45 patients 31 were 20 years old or less and 5 were over 35 years of age. The average age was 20.4 years. Zuidema $^{19}$ recorded that most of his Indonesian patients were young adults. In Britain, Howat ${ }^{13}$ indicated that 1 out of 17 patients was under 20 years of age and nine were between 20 and 30 . On the other hand, the youngest patient in the six cases reported by Pollock ${ }^{15}$ was 45 years. In France the mean age of 100 patients according to Sarles et al. ${ }^{16}$ was 38.4 years.
In the United States of America pancreatic calcification is a disease of middle age ; Wirts and Snape ${ }^{8}$ found an average age of 38.6 years in 24 patients. Edmondson et al. ${ }^{11}$ reported 26 patients whose ages varied from 22 to 86 . Thus pancreatic calcification occurs in younger age groups in Western Nigeria, whereas it is a disease of middle-aged people in Western Europe and the United States of America.

The sex incidence in this series suggests that men are more often afflicted than women, roughly in the ratio of 3 to 2 . It is, however, relevant to point out that males attend this hospital in greater number and more frequently than females. It is therefore likely that the sex incidence found in this series may not reflect the true sex incidence of this disease in the community at large. In Indonesia ${ }^{19}$ males and females were equally affected. Of the 100 patients reported in France ${ }^{16}$ 93 were males. In Britain, 10 out of 17 patients reported by Howat ${ }^{14}$ were females, whereas there were four males out of six patients reported by Pollock. ${ }^{15}$ Wirts and Snape ${ }^{8}$ recorded that males are five times more of ten affected than females, and Gambill and Pugh $^{10}$ indicated that the ratio of males to females was $4: 1$ in the United States of America.

\section{Symptoms}

Diabetes mellitus is the commonest presenting feature of pancreatic calcification in this series (Table II) ; $82 \%$ of the patients presented with symptoms of diabetes-namely, polyuria, polydipsia, and loss of weight. Zuidema ${ }^{19}$ found that 16 out of 18 patients (89\%) with pancreatic calcification had diabetes. Haggard and Kirtley, ${ }^{2}$ in a review of 204 cases, found the incidence of diabetes to be $9 \cdot 2 \%$, and Kaplan ${ }^{26}$ reported an incidence of $34 \%$. Nuzum ${ }^{27}$ observed disturbed carbohydrate tolerance in $50 \%$, and $\mathrm{King}^{25}$ recorded an incidence of $56 \%$ in the world literature since 1940 . Gambill and Pugh $^{10}$ reported that diabetes occurred in $23 \%$ of cases of calcified pancreas, and Cattell and Warren ${ }^{28}$ said that the incidence was $30-40 \%$. In France Sarles et al. ${ }^{16}$ found true diabetes in $23 \%$ and diminished glucose tolerance in $24 \%$. Howat $^{14}$ in Britain reported that 9 out of 18 cases were diabetic $(50 \%)$. Marks and Bank ${ }^{17}$ in South Africa found an incidence of $48.6 \%$. There appears to be a much higher inciderte of diabetes in pancreatic calcification in Western Nigeria and Indonesia, both tropical countries, than in Western Europe, U.S.A., and temperate South Africa (Table IV). This finding justifies the routine radiological abdominal investigations in some tropical diabetic clinics. ${ }^{2-24}$

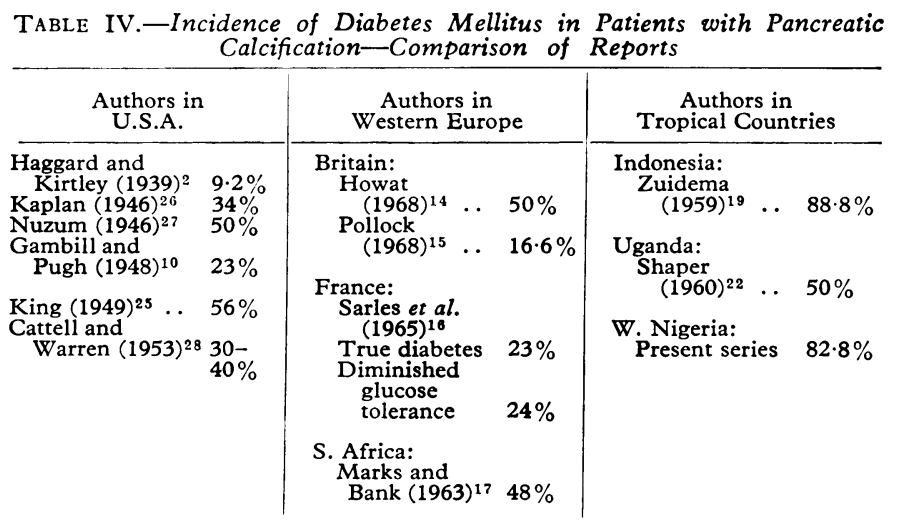

\section{Abdominal Pain}

Twenty-eight of 45 patients $(62 \%)$ in this series gave a history of abdominal pain at one time or another in the course of their illness. In some cases the history was vague and indefinite ; in some the history of pain was extracted by direct questioning. The use of interpreters in this hospital tended to confuse the issue. All sorts of abdominal discomforts were often described or interpreted as pain. The fact that diabetic 
ketosis per se was often associated with abdominal complaints ${ }^{23}$ did not help matters. In some patients, however, definite descriptions of the abdominal pain were recorded. In four the pain was severe, recurrent, epigastric, and referred to the back. Three of these four patients had raised serum amylase of over 1,000 Somogyi units. Of the remaining 24 patients, 17 had epigastric pain which was recurrent for variable numbers of years. In only five patients was the pain of recent short duration. In 17 of the 45 patients, however, there was no history of abdominal pain at all.

Abdominal pain appears to be the most prominent symptom in this malady in most of the reported cases. In Britain, Howat ${ }^{14}$ reported an incidence of pain in $94 \%$ of his cases. Sarles et al. ${ }^{16}$ in France recorded pain in $93 \%$ of 100 patients. In a report of 27 cases in the United States of America, Gambill, Comfort, and Baggenstoss ${ }^{29}$ reported pain in all their patients ; and Edmondson et al., ${ }^{11}$ in a review of 26 patients, recorded pain in $10(38 \%)$. Shaper ${ }^{22}$ in Uganda reported that 13 out of 18 patients $(72 \%)$ had abdominal pain. On the other hand, Zuidema ${ }^{19}$ said that none of his Indonesian patients had pain. It is obvious from these reports and our own experience that, though abdominal pain is the commonest symptom of pancreatic calcification, yet a good number of these patients have no pain at all-the so-called "silent" pancreatic calcification.

\section{Steatorrhoea}

Only three patients in this series complained of diarrhoea, but clinical and laboratory evidence (fat balance test) of steatorrhoea was found in 15 . Close direct questioning revealed that many of these 15 had had more frequent defaecations than normal, but they thought little of it ; indeed, a few were quite pleased. Steatorrhoea is the third commonest feature in this series; it occurred in $33 \%$ of the patients. Howat ${ }^{14}$ found steatorrhoea in 7 out of 18 patients $(38.8 \%$ ) with pancreatic calculi, and Sarles et al. ${ }^{16}$ reported a $17 \%$ incidence of steatorrhoea. Gambill and Pugh ${ }^{10}$ recorded an incidence of $18 \%$. Malabsorption in this disease is due to deficiency of pancreatic digestive exocrine enzymes as a result of atrophy and of fibrous and calcareous destruction of the acini. All our patients with steatorrhoea responded satisfactorily to pancreatin therapy.

\section{Loss of Weight}

There was a definite history of loss of weight in 30 patients (67\%). Clinically, 40 patients $(89 \%)$ were below the normal weight when first seen in the hospital. Most of the patients could neither read nor write and very few of them would know how to use a weighing machine. In this circumstance the evidence for loss of weight as complained by the patient was very scanty and unreliable. On direct questioning, however, it was not difficult to find that the collar of the shirt had become loose, or that the patient had had to shift to one or more inner holes in his waist belt, or that the wristwatch strap had become loose and he had had to make a new hole in it. The real trouble was encountered in those who did not use these articles, and there were many of them.

\section{Pancreatic Cyst}

Three patients had pancreatic cysts which were diagnosed radiologically. One presented with a painless epigastric mass of eight months' duration. The other two presented with mild, dull epigastric pain. One of them had unexplained melaena. But none of the three patients had diabetes or steatorrhoea. There was no history of trauma or episodes of severe epigastric pain. The incidence of pancreatic cyst in this series is $7 \%$. This figure is similar to that of Gambill and Pugh ${ }^{10}(5 \%)$ and of Howat ${ }^{1.4}(5 \cdot 5 \%)$. But higher figures are reported by Sarles et al. ${ }^{16}(26 \%)$ and Marks and $\operatorname{Bank}^{17}(18.9 \%)$. It is perhaps surprising that clinical pancreatic cysts are not more numerous in our series, because dilatation of the ducts and ductules and microcyst formations are prominent histological features of calcareous pancreas.

\section{Complications}

Pancreatic calcification often presents with the symptoms due to one of its complications. Table $\mathrm{V}$ gives a list of the complications met with in our series and in other reports. It also shows the differences and similarities in the tropical and temperate countries.

Diabetes mellitus, steatorrhoea, and pancreatic cysts have been discussed. Pulmonary tuberculosis is listed as a complication by some authors. ${ }^{81116}$ Five cases of pulmonary tuberculosis were accidentally discovered in this series. Pulmonary tuberculosis is a prevalent disease in the Western State of Nigeria. Tuberculosis is also a well-recognized complication of diabetes mellitus. Four of the five patients were diabetic. It is therefore arguable whether or not pancreatic calcification per se predisposes the sufferer to pulmonary tuberculosis in this series. We think that the pulmonary tuberculosis is more a complication of diabetes than pancreatic calcification per se. We also regard the bilateral cataracts seen in four patients and the peripheral neuropathy seen in two as complications of diabetes mellitus. The four patients with cataracts gave histories of defective vision of relatively rapid onset. All the cataracts were of the snowflake diabetic type. Gastrointestinal bleeding occurred in two of our patients $(4.4 \%)$. One patient with pancreatic cyst had melaena for which no cause was found at operation. The other patient bled to death from a chronic duodenal ulcer. Gambill and Pugh ${ }^{10}$ reported gastrointestinal bleeding in $8 \%$ of their patients. Of the 100 patients of Sarles et al., ${ }^{16}$ seven had haematemesis and two had melaena. None of the patients in our series was addicted to opiates or alcohol.

\section{Aetiology}

Acute pancreatitis with fat necrosis may be followed by pancreatic calcification, 12.2 .311 though this type is relatively rare.

Chronic relapsing pancreatitis is generally accepted as a predisposing factor in pancreatic calcification in Europe, ${ }^{13} 1416$ and in the United States of America. ${ }^{8} 12.2 .528$ Pancreatic calcification is a late stage in the progression of chronic relapsing

TABle V.-Complications of Pancreatic Calcification-Summary of Revicw of the Litcrature

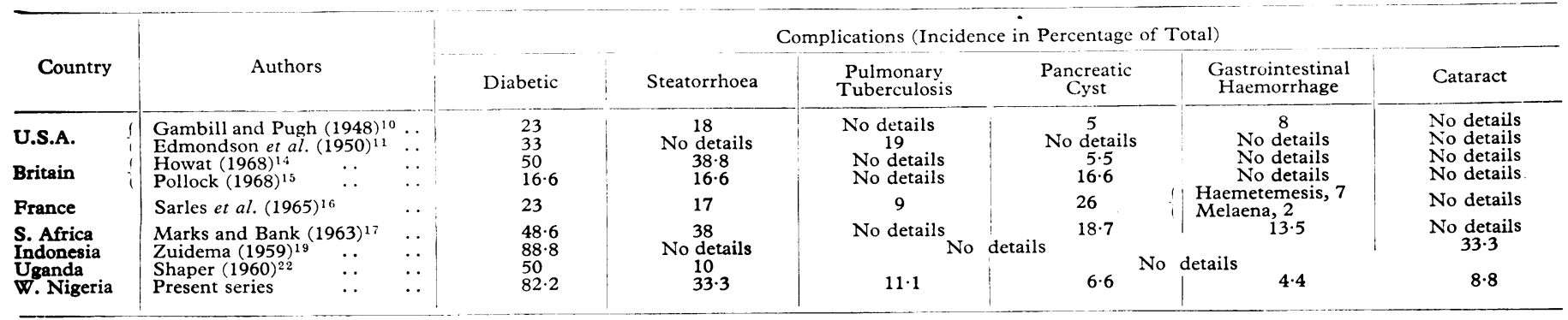


pancreatitis or chronic pancreatitis. $\mathrm{King}^{25}$ and Allbritten and Pressly ${ }^{31}$ are of the opinion that calcification occurs in $50 \%$ of cases of chronic relapsing pancreatitis. Of Howat's ${ }^{\mathbf{1 4}}$ 54 cases of chronic pancreatitis 17 have pancreatic calculi $(31.5 \%)$. In the present series 3 out of 45 patients satisfy the criteria enumerated by Gambill and $\mathrm{Pugh}^{10}$ and are accepted cases of chronic relapsing pancreatitis. The three patients had recurrent upper abdominal pain lasting hours or days for many years and each had supernatural concentration of serum amylase of over 1,000 Somogyi units, and, of course, pancreatic calcification. Three other patients who might have had chronic pancreatitis were not acceptable because they did not satisfy the criteria referred to above. Special pancreatic insufficiency investigation with secretin or secretin-pancreozymin ${ }^{1332}$ were not done in the patients in this series. Zuidema ${ }^{19}$ and Shaper ${ }^{22}$ found no evidence to incriminate chronic relapsing pancreatitis in Indonesia and Uganda respectively. Chronic relapsing pancreatitis is a rare cause of pancreatic calcification in tropical countries.

Alcoholic pancreatitis is a major cause of pancreatic calcification in South Africa, ${ }^{17}$ France, ${ }^{16}$ and the United States of America. ${ }^{71}$ In Britain alcoholism is not yet a documented cause of pancreatic calcification. Howat ${ }^{14}$ reported alcoholism in 1 out of 17 patients. Shaper ${ }^{22}$ in Uganda recorded the history of a large intake of local beer in 4 out of 20 patients. Banwell et al. ${ }^{23}$ noted alcoholic excess in 8 out of 12 patients, also in Uganda. Zuidema ${ }^{19}$ found no evidence of alcoholism in Indonesia. In none of the 45 patients in the present series was there a history of alcoholism. Perhaps an indirect evidence against alcoholism in this group is that $69 \%$ of the patients were under 20 years of age.

Martin and Canseco ${ }^{7}$ reported a case of pancreatic calcification due to hyperparathyroidism caused by an adenoma of one of the parathyroid glands. The patient also had calculi in the kidneys, prostate, and urinary bladder. The serum calcium was $14 \mathrm{mg} . / 100 \mathrm{ml}$. of blood. Howart ${ }^{13}$ also reported that in 1 of his 17 patients hyperthyroidism was responsible for the calcification of the pancreas. In 20 of our 45 patients in which details were given the serum calcium was within normal limits (Table III). There was no clinical evidence of hyperparathyroidism in any of the 45 patients.

Schistosomiasis ( $S$. haematobium) caused pancreatic calcification in one patient in this series. This was an interesting finding. A thorough search of the world literature revealed no previous report of schistosomal pancreatic calcification. Extensive deposits of schistosoma ova are not uncommon necropsy findings in this country, ${ }^{27}$ but what is unusual is widespread calcification of the ova in tissues other than the ureters and the urinary bladder. In this patient calcified ova were found in the liver, pancreas, ureters, bladder, three abdominal lymph nodes, and the wall of pulmonary arteries, arterioles, veins, and capillaries. In two other patients pancreatic calcification and urinary bladder calcification were present and schistosoma ova were found in the urine. There was no necropsy evidence in these latter two cases to incriminate schistosomiasis for the pancreatic calcification.

Zuidema $^{19}$ postulated that protein malnutrition was the cause of pancreatic fibrosis and calcification in Indonesia. Shaper $^{22}$ in Uganda supported this hypothesis. We have shown above that chronic relapsing pancreatitis or chronic pancreatitis is an uncommon cause of pancreatic calcification in this series. Biliary disease was noted in only one patient, but the non-functioning gall bladder contained no stones and the patient had no history of obstructive jaundice. Kwashiorkor is "endemic" in this community and many of our patients would have suffered from protein malnutrition in early life. Eleven patients were clinically malnourished on first attendance ; $69 \%$ of our patients were under 20 years of age when first seen. Many of them (89\%) were underweight on this first attendance. Indeed, our patients lived in circumstances similar to those in Uganda and Indonesia. We are therefore of the opinion that protein malnutrition predisposed the pancreas to fibrosis and calcification in over $90 \%$ of our patients.

\section{Pathogenesis}

The genesis of pancreatic calcification is not fully understood, but fibrosis appears to be a basic element that predisposes the pancreas to calcareous deposition. In chronic relapsing or chronic pancreatitis ${ }^{7-17}$ and protein malnutrition ${ }^{182233}$ the destroyed pancreatic tissue is replaced by fibrous tissue which proliferates to form extensive interlobular, intralobular, periductal, and periacinar fibrosis. The acini atrophy and the islets of Langerhans are destroyed, the ducts and ductules are dilated, and small cysts are formed..$^{81116}$ In schistosomiasis the ova actively provoke tissue reaction, which ultimately results in fibrosis ${ }^{34}$ and calcification. Extensive fibrosis of the pancreas inevitably leads to obstruction of the ducts and ductules, with resultant stagnation of exocrine secretions. The sequence of events appears to be obstruction, stagnation, and infection, which favours calcium deposition in the pancreas. ${ }^{28}$

We thank our colleagues in the department of medicine for permission to study their patients, and also our colleagues in the department of morbid anatomy for their help in preparing the slides used in this paper. Mr. A. O. Enyogai, of the department of medical illustration unit, and his co-workers have been most helpful. We are grateful to our departmental secretaries for their repeated hard work in the course of this investigation.

\section{REFERENCES}

Graaf, R. de, quoted by Haggard and Kirtley. ${ }^{2}$

Haggard, W. D., and Kirtley, J. A., Annals of Surgery, 1939, 109, 809.

Gillies, C. L., American fournal of Roentgenology, 1939, 41, 42.

King, A. B., and Waghelstein, J. M., Archives of Internal Medicine, $1942,69,165$.

5 Lionello, J., Ficarra, B. J., and Ryan, N. H., Archives of Surgery,

1944, 48, 137. $1936,11,456$.

Martin, L., and Canseco, J. D., fournal of the American Medical Association, 1947, 135, 1055 .

${ }^{8}$ Wirts, C. W., and Snape, W. J., American fournal of Medical Science, $1947,213,290$.

9 Domzalski, C. A., Annals of Internal Medicine, 1949, 31, 650.

Gambill, E. E., and Pugh, D. G., Archives of Internal Medicine, $1948,81,301$

${ }^{1}$ Edmondson, H. A., Bullock, W. K., and Mehl, J. W., American Journal of Pathology, 1950, 26, 37.

12 Kneidel, J. H., Annals of Internal Medicine, 1951, 34, 790.

Howat, H. T., Practitioner, 1963, 191, 42.

Howat, H. T., Postgraduate Medical fournal, 1968, 44, 733.

Pollock, A. V., Postgraduate Medical fournal, 1968, 44, 737.

Sarles, H., et al., Gut, 1965, 6, 545.

Marks, I. N., and Bank, S., South African Medical fournal, 1963, 37, 1039 .

18 Zuidema, P. J., Tropical and Geographical Medicine, 1959, 11, 24.

20 Mahadevan, R., British Medical fournal, 1961, 1, 626.

${ }_{21}$ Ratnaike, V. T., and Rajasuriya, K., Tropical and Geographical Medicine, 1963, 15, 1 .

22 Shaper, A. G., Lancet, 1960, 1, 1223.

${ }_{23}$ Banwell, J. G., Campbell, J., Blackman, V., Hutt, M. V., and Leonard, P., East African Medical Fournal, 1963, 40, 277.

${ }^{24}$ Kinnear, T. W. G., East African Medical fournal, 1963, 40, 288.

${ }_{25}$ King, S. E., Medical Clinics of North America, 1949, 33, 883.

${ }^{26}$ Kaplan, M. H., New Orleans Medical and Surgical fournal, 1946, 99,

2: Nuzum, F. R., Journal of the American Medical Association, 1946, $132,574$.

${ }^{28}$ Cattell, R. B., and Warren, K. W., Surgery of the Pancreas, 1953. Philadelphia, Saunders.

${ }^{29}$ Gambill, E. E., Comfort, M. W., and Baggenstoss, A. H., Gastroenterology, 1948, 11, 1 .

${ }^{30}$ Edmondson, H. A., and Fields, I. A., Archives of Internal Medicine, $1942,69,177$.

Allbritten, F. F., and Pressly, C. L., Surgical Clinics of North America, 1950, 30, 1627.

32 Burton, P., Harper, A. A., Howat, H. T., Scott, J. E., and Varley, H., Gut, 1960, 1, 193.

33 Davies, J. N. P., Lancet, 1948, 1, 317.

3. Faust, E. C., American fournal of Tropical Medicine, 1948, 28, 175. 